\title{
Designing Inclusive Environments in Healthcare with a Focus on Bariatric Patients
}

\author{
Meghna Vij ${ }^{1}$, Naved A. Ariyana ${ }^{2}$ \\ ${ }^{1}$ Amity University, Amity School of Architecture and Planning, Panchgaon, Manesar, Haryana 122413 \\ ${ }^{2}$ Healthcare Architect, R-183, Lane No. 9, Ramesh Park, Laxmi Nagar, New Delhi 110092
}

\begin{abstract}
Bariatric is the term used to define extreme obesity. Globally a number of people have been dying each year because of being obese or overweight of which India comes at the third number after USA and China which has a large section of obese people. Obesity is one of the major health problems in the world which is rising due to the lifestyle changes. Excessive obesity leads to various diseases and reduced life expectancy. The healthcare facilities hence should keep in mind about these people so that they do not feel overlooked. Bariatric patients face certain difficulties such as mobility and taking care of themselves. Due to their unmanageable weight often they need the help of others which includes accessing the facilities like hygiene, stairs, ramps, furniture, doors etc. The major design consideration involved in the research includes appropriate planning of space, furniture and equipments and patient care and safety while handling these patients. In India a lot of hospitals have been providing bariatric surgeries but still there is a need to follow a new approach give special focus on the spaces, furniture and the proper training given to the staff to handle these people. A new approach needs to be followed and the healthcare professionals and architects need to work together in order to provide better spaces for the bariatric clients too.
\end{abstract}

Keywords: bariatric patients, healthcare, space considerations, equipment needs, patient handling.

\section{Introduction}

Bariatric may be defined as the science which considers the distribution of the patient's weight throughout the body of which calculating the body mass index (BMI) is the most commonly used. According to WHO, the people with BMI 30 or more are considered obese and with BMI 40 or greater as severely obese. These people face a lot of issues like mobility and access to certain areas like ramps, staircase, toilets, falling risks, reduced life spans and the increased risk of being prone to many diseases, skin problems and difficulty in handling their own self due to the unmanageable weight other than non bariatric people. Though the healthcare providers wish to offer quality care to these people yet the spaces and furniture designed, the equipments used and the training given to the staff for handling such people still needs to be taken into account. The architects and healthcare professionals need to come together for the optimum use of spaces, equipments and the care given to the bariatric people.

\section{Bariatric patients and health issues}

The bariatric patients are often more prone to health problems such as difficulty in sleeping and the need of breathing devices to help them sleep. If they have been bariatric for a significant period of time, their life span may be reduced by as much as $10-15$ years compared to the nonbariatric population. They are more prone to chronic illness, including cardiac disease; hypertension; respiratory disease; diabetes; skin conditions, such as dermatitis and ulcers; osteoarthritis; stress incontinence; hyperlipidemia; depression; decreased self esteem; certain types of cancers; and gallbladder disease. [(Marylou Muir R. C., 2009, January 31)]
In the eight cities for which separate estimates of nutrition are available from NFHS-3 (Chennai, Delhi, Hyderabad, Indore, Kolkata, Meerut, Mumbai, and Nagpur), the prevalence of under nutrition and over nutrition among women and men ranges widely. [(Fred Arnold S. P., 200506)]

Table 1: Nutritional status of Women and Men 15-49 years by City and Slum/Non-slum area

\begin{tabular}{|c|c|c|c|c|}
\hline \multicolumn{2}{|c|}{ \% of women overweight } & \multicolumn{2}{c|}{ \% of men overweight } \\
\hline City/area & Too thin & Obese & Too thin & Obese \\
\hline Delhi & $\mathbf{1 4}$ & $\mathbf{2 7}$ & $\mathbf{1 5}$ & $\mathbf{1 8}$ \\
\hline Slum & 21 & 20 & 22 & 11 \\
\hline Non-slum & 13 & 29 & 13 & 20 \\
\hline Chennai & $\mathbf{1 6}$ & $\mathbf{3 9}$ & $\mathbf{2 3}$ & $\mathbf{2 3}$ \\
\hline Slum & 18 & 34 & 27 & 18 \\
\hline Non-slum & 15 & 41 & 22 & 25 \\
\hline Hyderabad & $\mathbf{2 1}$ & $\mathbf{3 3}$ & $\mathbf{2 2}$ & $\mathbf{2 5}$ \\
\hline Slum & 21 & 31 & 25 & 22 \\
\hline Non-slum & 21 & 34 & 21 & 25 \\
\hline Indore & $\mathbf{2 5}$ & $\mathbf{2 2}$ & $\mathbf{2 1}$ & $\mathbf{1 4}$ \\
\hline Slum & 33 & 19 & 26 & 9 \\
\hline Non-slum & 23 & 23 & 20 & 15 \\
\hline Kolkata & $\mathbf{1 6}$ & $\mathbf{3 0}$ & $\mathbf{2 0}$ & $\mathbf{1 8}$ \\
\hline Slum & 21 & 25 & 23 & 15 \\
\hline Non-slum & 14 & 32 & 19 & 20 \\
\hline Meerut & $\mathbf{2 0}$ & $\mathbf{3 0}$ & $\mathbf{2 3}$ & $\mathbf{1 9}$ \\
\hline Slum & 22 & 25 & 26 & 16 \\
\hline Non-slum & 19 & 34 & 21 & 21 \\
\hline Mumbai & $\mathbf{2 2}$ & $\mathbf{2 7}$ & $\mathbf{2 5}$ & $\mathbf{1 8}$ \\
\hline Slum & 23 & 25 & 26 & 16 \\
\hline Non-slum & 21 & 30 & 23 & 21 \\
\hline Nagpur & $\mathbf{3 1}$ & $\mathbf{1 9}$ & $\mathbf{3 5}$ & $\mathbf{1 3}$ \\
\hline Slum & 36 & 14 & 41 & 10 \\
\hline Non-slum & 28 & 23 & 31 & 16 \\
\hline \multicolumn{2}{|c|}{} & & & \\
\hline
\end{tabular}




\section{International Journal of Science and Research (IJSR) \\ ISSN (Online): 2319-7064}

Index Copernicus Value (2013): 6.14 | Impact Factor (2015): 6.391

Source: Fred Arnold, S. P. (2005-06). Nutrition in India National Family Health Survey (NFHS-3) India. Mumbai: Government of India.

\subsection{Handling bariatric patients}

The hospital staff faces a lot of problems while handling these patients as too much of risks are involved in daily activities such as hygiene, mobility, reaching and risk of falling. The activity of elevating a limb, which is often necessary for completing a dressing change, is especially dangerous. One leg is approximately $16 \%$ of a person's total body weight [(Marylou Muir R. C., 2009, January 31)].

\section{Design Factors \& Equipment Needs}

The designers should be careful while designing and planning of spaces and equipment to ensure a dignified and quality patient care to be given to the bariatric people. Large spaces are needed to accommodate the various equipments like beds, stretchers, wheelchairs, transfer bench, mechanical lifts etc. Here are some few factors that need to be taken into account while designing the hospitals for the bariatric people;

- Patient population

- Planning for larger patient needs and larger equipments.

- Patient ambulation in terms of building entrances, width of doorways, corridors, waiting areas.

- Patient treatment rooms and toilets.

- Staff education and training to assist bariatric patients.

\subsection{Patient Population}

While designing the bariatric facilities, the first thing to be considered is the ratio of the bariatric patients population to the entire patient population in a hospital in order to decide the number of rooms keeping in mind the future needs of this population.

\subsection{Planning for patient needs and larger equipment}

According to a primary survey done in a few hospitals of New Delhi, the researchers found that there is an increase in the number of bariatric patient population every year and fulfilling the needs of such population can provide better satisfaction and dignity to such patients which in turn can lead to better quality, efficiency and greater customer satisfaction. Spaces should be able to take in larger equipments like the bariatric bed with an expandable deck and bariatric stretcher, the patient lift system for instance the portable ceiling lifts, the floor lifts and the inflatable lifts to lift up a fallen patient, walkers, heavy duty wheelchairs, full body slings or specialty slings for example limb slings, pneumatic tilt tables, and visitors chairs to sit comfortably and safely.

\subsection{Building entrances}

The building entrances should be wide enough with appropriate ramps and handrails with wheelchairs available at the entrance for the easy access. Establish an accessible path from the hospital entrance to all major departments by accommodating for a 39 " by 49 " wide wheelchair with a 6 ' turning radius. [(Inpro, 2012)]

\subsection{Width of doorways, corridors and waiting areas}

The width of the doorways should be as such to provide a barrier free environment. Doors for exam rooms are recommended to be 3'6" wide and the recommended opening size for patient rooms and procedure areas is 4'0". Alternatively paired doors or sliding doors on overhead tracks can be used for these wider doorways. [(Andrew Collignon J. )] For one bariatric and one non bariatric patient to walk through a corridor a minimum of 5 ' 0 " wide corridor is needed.
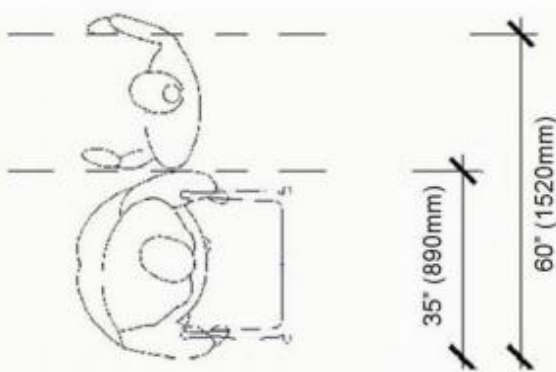

Figure 1: Corridor width

(Source:https://www2.worksafebc.com/PDFs/healthcare/Bari atric/design_guidelines.pdf)

At least twenty five percent of bariatric chairs should be provided in the patient waiting areas. It should also be taken care that the furniture for bariatric patients gets fused up with the standard furniture so that the obese patients do not feel discomfort. The width of the wheelchair should be at least 2'7" for a bariatric patient and 4'4" clear opening is required for the stretcher delivery. [(Susana D. Andrade, 2006)]
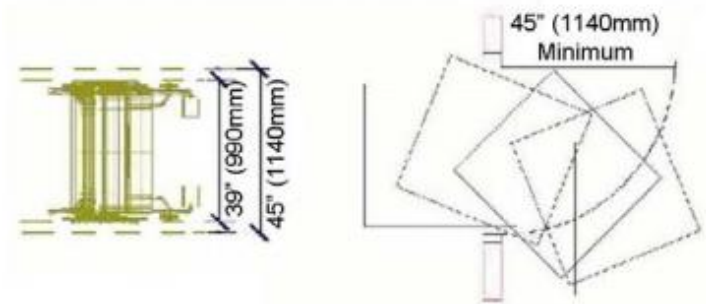

Figure 2: Doorway width at exam rooms and outpatient toilet

(Source; Planning and Design Guidelines for Bariatric Healthcare Facilities, AIA academy Journal)

\subsection{Patient treatment rooms and toilet}

The patient rooms should also be bigger in size than the standard patient rooms to accommodate the bariatric beds. While planning the patient rooms it should be remembered that the attendant accompanying the patient, maybe his family member might also be obese. The size of the bariatric stretcher/beds is different from the standard beds/ stretcher. The minimum width for the bariatric beds is 3 ' 6 " and that of the bariatric chair if 2 ' 8 '. According to a survey, it was found that the clear space required to transfer a patient from 


\section{International Journal of Science and Research (IJSR) \\ ISSN (Online): 2319-7064}

Index Copernicus Value (2013): 6.14 | Impact Factor (2015): 6.391

bed to chair using mobile lift was 7'0"X 10'6". This clear space shall not be less than 2'6" from the room's headwall and shall be adjacent to the patient bed and the patient transfer using an overhead ceiling lift requires 5'0" X 10'6" clear space. The door of the toilets should be wide enough for two caregivers to assist the patient. The minimum toilet door width suggested is 3'6". Floor mounted toilets should be installed to bear the weight (at least $300 \mathrm{kgs}$ ) as wall mounted commodes are not safe for the use of bariatric patients. Also, instead of installing floor mounted sinks wall mounted sinks should be preferred to avoid obstruction of the wheelchair. Grab bars should be installed on the side walls of the toilet to provide support. Transfer bench can be used in the bathing area to assist the patient move into and out of the bathtub. A bariatric cart with items such as large hospital gowns, pants, slippers should be provided for the patients.

\subsection{Staff education and training to assist bariatric patients}

Proper training and education should be given to the staff for handling the bariatric patients as there are a lot of risks involved. A caregiver might be injured severely and may experience severe physical injuries during the repositioning and turning of the patient, lateral transfers, and other injuries related to mobility of the patient.

\section{Conclusion}

Today a lot of people generally adopt unhealthy food habits and lifestyle which are considered to be a major cause of obesity. Most of the hospitals in India are not well equipped to accommodate the needs of the obese people. The healthcare professionals and doctors must work in collaboration to provide a bariatric friendly environment which gives care considering the physical as well as emotional needs of this population with quality and dignity. Following specific standards which may be accepted universally can help cater the situation. Providing optimum spaces, instruments and furnishings and giving education and training to the staff regarding the challenges faced during their care can help improve the patient's faith and improve the efficiency of the hospitals. The bariatric population should not be treated as a secluded part of the society and should be given care with equality and honour.

\section{References}

[1] [1,3] Marylou Muir, R. C. (2009, January). Essentials of a Bariatric Patient Handling Program. The Online Journal of Issues in nursing , 2 of 8.

[2] Fred Arnold, S. P. (2005-06). Nutrition in India National Family Health Survey (NFHS-3) India. Mumbai: Government of India.

[3] Inpro Corporation, I. (2012, january). BARIATRIC DESIGN 101. An introduction to the Design Consideration.

[4] Andrew Collignon, J. (n.d.). Strategies for Accommodating Obese Patients in an Acute Care Setting. The American Institute of Architects
[5] Susana D. Andrade, H. G. (2006). Planning and Design Guidelines for Bariatric Healthcare Facilities: 2004-2005 Fellowship Research. The American Institute of Architects , 57. 